\title{
Práticas pedagógicas num Território Educativo de Intervenção Prioritária
}

\author{
Fernanda Bastos ${ }^{1}$ \\ Cristina Costa-Lobo ${ }^{1}$ \\ Carla Santos Pereira ${ }^{1}$
}

\section{Resumo}

Este estudo segue a linha teórica de diversos autores, entre eles, Abelha, Machado e Costa Lobo (2014), Roldão (1999a, 1999b, 2007a), Hargreaves (1998) e Alarcão (2003), e cumpre o propósito de estudar o trabalho colaborativo entre os docentes do Agrupamento de Escolas D. Pedro I, no norte de Portugal. Esse Agrupamento, no qual uma das autoras deste trabalho exerce funções docentes, faz parte dos Territórios Educativos de Intervenção Prioritária (TEIP). Utilizamos um design metodológico do tipo quantitativo, que permitiu estudar as diferentes opiniões dos professores pertencentes ao contexto educativo em estudo, acerca das suas representações sobre as dinâmicas de trabalho colaborativo e das suas concepções sobre conceitos como currículo, gestão curricular, desenvolvimento curricular e projeto educativo. As informações recolhidas foram submetidas a análises estatísticas, com o apoio da ferramenta informática de cálculo Statistical Package for the Social Sciencies (SPSS), versão 22. Perante os resultados obtidos, somos então confrontados com o alcance do objetivo inicial deste estudo, isto é, a compreensão da apropriação dos respondentes relativamente aos conceitos já elencados, bem como a compreensão da gestão que fazem do currículo, a caracterização das dinâmicas de trabalho e a avaliação das alterações manifestas quanto à satisfação dos docentes com a dinâmica de trabalho, mediante as características pessoais e profissionais dos inquiridos. Em suma, este Agrupamento pode ser considerado um exemplo de boas práticas colaborativas, com uma gestão eficaz e uma liderança que apoia, incentiva e motiva os seus docentes. Esta investigação deixa em aberto potenciais cenários futuros de investigação e intervenção no domínio da escola reflexiva, privilegiando as culturas escolares de referência.

\section{Palavras-chave}

Dinâmicas de trabalho cooperativo - Currículo - Satisfação dos docentes - Territórios Educativos de Intervenção Prioritária.

\footnotetext{
1- Universidade Portucalense Infante D. Henrique, Porto, Portugal.

Contatos: fmbleite@gmail.com, ccostalobo@gmail.com, carlasantos@uportu.pt
} 


\title{
Pedagogical Practices in an Educational Territory of Priority Intervention
}

\begin{abstract}
This study follows the theoretical line of various authors, among them Abelha, Machado, Costa Lobo (2014), Roldão (1999a, 1999b, 2007), Hargreaves (1998), and Alarcão (2003), and examines collaborative work among the teachers of D. Pedro I School Cluster, in North Portugal. This school cluster is part of the Educational Territories of Priority Intervention. We have used a quantitative methodological design to analyze the teachers' different opinions and representations of the dynamics of collaborative work, their conceptions of curriculum, curriculum management, curriculum development, and educational projects. The information was subjected to statistical analysis, with the support of Statistical Package for Social Sciences (SPSS), version 22, a calculation software tool. Given the results obtained, we have been faced with the scope of the initial purpose of this study, that is, examining respondents' understanding of the concepts listed above, how they manage the curriculum, the characterization of work dynamics, and the evaluation of the changes regarding the teacher satisfaction about work dynamics according to the personal and professional characteristics of the respondents. In short, this cluster can be considered an example of good collaborative practices, with effective management, and leadership that supports, encourages and motivates its teachers. This study opens up potential future scenarios of research and intervention in the field of reflective school, focusing on school cultures of excellence.
\end{abstract}

\section{Keywords}

Collaborative work - Curriculum development - Educational project

\section{Introdução}

Este estudo segue a linha teórica de diversos autores, entre eles, Abelha (2011), Roldão (2007a, 2007b), Hargreaves (1998), Alarcão (2003) e Costa Lobo (2011), e cumpre o propósito de estudar o trabalho colaborativo entre os docentes do Agrupamento de Escolas D. Pedro I, que se situa na região do Grande Porto, mais concretamente na cidade de Vila Nova de Gaia, zona litoral no norte de Portugal Continental.

Pretende apresentar contributos que potenciem possíveis discussões sobre a representação conceitual dos professores sobre temáticas como desenvolvimento curricular, gestão curricular, projeto educativo e, essencialmente, trabalho colaborativo. 
0 trabalho centra-se nas avaliações dos docentes sobre os referidos conceitos e qual o possivel impacto nas suas dinâmicas de trabalho.

Participaram os professores do agrupamento supramencionado, situado na freguesia de Canidelo, concelho de Vila Nova de Gaia e distrito do Porto. Este Agrupamento faz parte dos Territórios Educativos de Intervenção Prioritária (TEIP).

Neste estudo, rentabilizou-se essencialmente o instrumento de trabalho de inquérito por questionário, que nos pareceu o mais adequado tendo em conta o tipo de investigação que se pretendia.

Utilizamos um design metodológico do tipo quantitativo, que permitiu conhecer as diferentes opiniões dos professores pertencentes ao contexto educativo em estudo, acerca das suas representações sobre as dinâmicas de trabalho colaborativo e das suas concepções sobre conceitos como currículo, gestão curricular, desenvolvimento curricular e projeto educativo. As informações recolhidas foram submetidas a análises estatísticas, com o apoio da ferramenta informática de cálculo Statistical Package for the Social Sciencies (SPSS), versão 22.

Perante os resultados obtidos, somos então confrontados com o alcance do objetivo inicial deste estudo, isto é, a compreensão da apropriação dos respondentes relativamente aos conceitos já elencados, bem como a compreensão da gestão que fazem do currículo, a caracterização das dinâmicas de trabalho e a avaliação das alterações manifestas quanto à satisfação dos docentes com a dinâmica de trabalho, mediante as características pessoais e profissionais dos inquiridos.

\section{Enquadramento do Agrupamento TEIP D. Pedro I}

0 Agrupamento de Escolas D. Pedro I, ao abrigo do Despacho Normativo n. ${ }^{\circ}$ 55/2008 de 23 de outubro, que substitui o Despacho de 26 de setembro de 2006, integra um Território Educativo de Intervenção Prioritária.

\section{Breve caracterização}

0 Agrupamento de Escolas D. Pedro I inclui populações de duas freguesias do concelho de Vila Nova de Gaia: Canidelo e uma parte de Santa Marinha que corresponde à anterior freguesia São Pedro da Afurada.

Ambas as freguesias apresentam carências graves, tanto no que se refere ao nível socioeconômico como cultural; no entanto, apresentam contrastes acentuados, pois, ao lado de famílias com inúmeras necessidades, existem zonas habitacionais de luxo, o que marca este agrupamento por um conjunto muito profundo de assimetrias.

Tanto na freguesia de Canidelo como na antiga freguesia de São Pedro da Afurada, existe uma elevada taxa de analfabetismo, com grandes carências econômicas juntamente com situações sociais bastante problemáticas. Tem havido um aumento de famílias em risco, de monoparentalidade, de famílias numerosas, e graves situações de negligência e de maus-tratos. Também nestas duas áreas se apresenta um elevado número de desempregados e de beneficiários de rendimento de inserção. 


\section{0 seu projeto educativo}

A importância do projeto educativo consagra-se na publicação do Decreto-Lei $n^{\circ}$ 172/91, de 10 de maio, que define o regime de direção, administração e gestão dos estabelecimentos de ensino, desde o pré-escolar até ao secundário e, mais recentemente, no Decreto-Lei n. ${ }^{\circ}$ 75/2008, de 22 de abril, que considera o projeto educativo, à semelhança do que já foi mencionado, como:

[...] o documento que consagra a orientação educativa do agrupamento de escolas ou da escola não agrupada, elaborado e aprovado pelos seus órgãos de administração e gestão para um horizonte de três anos, no qual se explicitam os princípios, os valores, as metas e as estratégias segundo os quais o agrupamento de escolas ou escola não agrupada se propõe cumprir a sua função educativa. (AZEVEDO, 2011, p. 14).

0 agrupamento, devido às suas características específicas, integra um Território Educativo de Intervenção Prioritária desde 2007 e incorpora no seu projeto educativo a pretensão de:

[...] promover uma escola humanista e integradora, responsável pelo percurso escolar dos seus alunos, aberta à participação de parceiros, capaz de fixar metas e avaliar os seus resultados, de se organizar, de proporcionar um clima de boa convivência, onde a formação integral de cada aluno, a aquisição dos saberes e a sua preparação para a vida ativa sejam os princípios orientadores. (AGRUPAMENTO..., 2013a, p. 10).

Tal como previsto na ideologia subjacente aos TEIP, também no projeto educativo do Agrupamento de Escolas D. Pedro I, está presente a necessária articulação com as entidades da comunidade, procurando, deste modo, a otimização dos recursos disponíveis e a mobilização das instituições presentes no meio em que está inserido, através da rentabilização de protocolos e parcerias. Pretende, assim,

[...] garantir uma escola de qualidade para todos, articulada com os serviços de apoio social à comunidade e com os serviços de saúde locais, visando um acompanhamento mais personalizado ao longo do percurso escolar dos alunos, garantido pelos meios do território educativo do Agrupamento" (AGRUPAMENTO..., 2013b, p. 11).

\section{0 seu projeto curricular}

Após a elaboração do projeto educativo do agrupamento, e com base neste, procedeu-se à elaboração do projeto curricular. De acordo com o exposto neste projeto, pretende-se que se baseie na "realidade social, económica e cultural do meio envolvente e reflita os valores, as preocupações e os interesses de todos” (AGRUPAMENTO..., 2013c, p. 2). Para tal, foi fundamental estudar o contexto em que o Agrupamento está inserido, trabalho, aliás, 
já realizado para a elaboração do projeto educativo, pois só assim foi possível adequar o currículo às diferentes necessidades.

0 projeto curricular de agrupamento é alvo de avaliação ao longo do ano letivo, cuja responsabilidade está a cargo de uma comissão de acompanhamento do Conselho Pedagógico, e da qual resulta um relatório anual, analisado e aprovado em Conselho Geral, e que serve à sua reformulação.

\section{Enquadramento metodológico da investigação}

A base da nossa investigação é um estudo de caso, no qual pretendemos aprofundar as concepções e dinâmicas de trabalho colaborativo entre os docentes do Agrupamento de Escolas D. Pedro I, atendendo aos fatores potencializadores dessas dinâmicas, bem como a eventuais constrangimentos.

De acordo com o conhecimento que pretendemos extrair deste estudo de caso, foram então estabelecidos os seguintes objetivos a atingir:

- identificar as concepções dos professores deste agrupamento sobre os conceitos de currículo, gestão curricular, desenvolvimento curricular, projeto educativo e trabalho colaborativo;

- compreender como os professores deste agrupamento gerem o currículo nos diferentes departamentos (Subdepartamentos [Pré/2\% $/ 3^{\circ}$ ciclo do ensino básico - CEB] e coordenações de ano $\left[1^{\circ} \mathrm{CEB}\right]$, e conselhos de turma $\left[2^{\circ} / 3^{\circ} \mathrm{CEB}\right]$ e unidades educativas [Pré/ $\left.\left.1^{\circ} \mathrm{CEB}\right]\right)$;

- caracterizar e compreender as dinâmicas de trabalho estabelecidas por estes professores no que diz respeito à gestão do currículo;

- avaliar se a satisfação dos docentes com a dinâmica de trabalho manifesta alterações mediante as características pessoais e profissionais dos inquiridos.

\section{Opções metodológicas}

Selecionamos um determinado contexto educativo e estudamos, a partir de um inquérito, as diferentes opiniões dos professores deste contexto, no que diz respeito à noção de trabalho colaborativo. Recolheram-se os dados no seu meio natural.

Este estudo decorreu no ano letivo de 2014/2015. Os inquéritos foram distribuídos no início do mês de janeiro de 2015, quando das reuniões dos docentes, e recolhidos até final do mesmo mês.

De um modo geral, pretendemos conhecer as representações que os docentes têm sobre as dinâmicas de trabalho colaborativo, e quais as suas concepções sobre currículo, gestão curricular, desenvolvimento curricular e projeto educativo.

\section{Questionário}

0 questionário por nós utilizado apresentou unicamente perguntas de resposta fechada, usando a escala ordinal de 1 (Discordo plenamente) a 4 (Concordo plenamente) 
para evitar que os respondentes caíssem na tentação do meio-termo, sem se comprometerem com uma determinada posição.

0 nosso inquérito está dividido em três partes. Na parte I, procuramos conhecer a caracterização pessoal e profissional dos inquiridos. Na parte II, dirigimo-nos à representação conceitual dos professores inquiridos, no que diz respeito às suas concepções de currículo, desenvolvimento curricular, gestão curricular, projeto e trabalho colaborativo. Na parte III, debruçamo-nos sobre as dinâmicas de trabalho docente, no que diz respeito à percepção dos professores deste agrupamento sobre o trabalho realizado pela direção, pelos subdepartamentos e coordenações de ano, e pelos conselhos de turma e unidades educativas. Ainda nesta parte do inquérito, houve intenção de conhecer as percepções destes docentes sobre a cultura do agrupamento, dos seus aspectos positivos e dos seus problemas.

\section{Amostra}

A nossa amostra abrangeu todos os professores deste agrupamento desde o Pré-Escolar até ao $3^{\circ} \mathrm{CEB}$.

Desta forma, acabamos por distribuir aproximadamente 160 inquéritos, o equivalente a cerca de 97\% do corpo docente do agrupamento em estudo, dos quais recebemos 106 devidamente preenchidos, o que dá uma amostra de cerca de 66\%, que constitui uma boa base de trabalho. A média das idades dos docentes deste agrupamento situa-se nos 45,9 anos, embora a moda esteja nos 41 anos de idade.

\section{Técnicas de tratamento de dados}

Após a recolha dos inquéritos, procedemos ao seu tratamento, momento que se assume de grande importância para atingir os objetivos elencados na presente investigação.

As informações recolhidas foram submetidas a uma análise estatística, com o apoio da ferramenta informática de cálculo SPSS, versão 22.

\section{Discussão dos resultados}

\section{- Caracterização pessoal e profissional dos professores respondentes ao questionário}

A média das idades dos docentes deste agrupamento é de 45,9 anos, embora a moda seja de 41 anos de idade. De salientar que o mais novo tem 32 anos e o mais velho (mas nem todos responderam a este item) tem 63 anos. Relativamente ao gênero, e confirmando os resultados de estudos elaborados sobre o gênero na profissão docente (ABELHA, 2011), também neste agrupamento há uma predominância do gênero feminino (82,1\% vs. 17, 9\%).

Para Huberman (2007), a experiência dos professores obedece a um ciclo de vida dependente de algumas tendências gerais. Assim, no que diz respeito ao tempo de serviço, os docentes do Agrupamento de Escolas D. Pedro I encontram-se majoritariamente no grupo entre os 7 e 18 anos, com 45,3\% dos inquiridos, o que, e obedecendo aos critérios do autor referido, corresponde à fase de estabilização. É uma altura em que o professor se poderá sentir mais seguro de si mesmo, apresentando uma "confiança crescente, o 
sentimento confortável de ter encontrado um estilo próprio de ensino, aposta a médio prazo, uma maior flexibilidade na gestão da turma” (HUBERMAN, 2007, p. 41).

A licenciatura é o grau de habilitações acadêmicas mais frequente, com 82,1\% dos respondentes. Sessenta e seis por cento são professores do Quadro de Agrupamento, com apenas 8,5\% de contratados, o que confere a este estabelecimento alguma estabilidade em termos de mobilidade do corpo docente, que se traduz na sua responsabilização e dedicação ao projeto educativo do agrupamento, que permite um aperfeiçoamento constante e com reconhecidas melhorias pelo trabalho realizado, que se vão refletir na qualidade de todo o processo de ensino e aprendizagem.

No que diz respeito aos cargos desempenhados, só 17,9\% dos inquiridos referem que não desempenham qualquer cargo na dinâmica do agrupamento. A esmagadora maioria dos inquiridos (que poderão igualmente desempenhar outros cargos), 51,9\%, são diretores de turma, ou professores titulares de turma no caso do pré-escolar ou do $1^{\circ} \mathrm{CEB}$.

\section{- Representação conceitual dos professores inquiridos}

Nesta parte do inquérito, preocupamo-nos em saber, segundo os professores inquiridos, qual o entendimento que tinham relativamente aos conceitos: currículo, desenvolvimento curricular, gestão curricular, projeto e trabalho colaborativo:

Assim, de forma a compreendermos o nível de apropriação destes conceitos [...] e na tentativa de evitarmos respostas politicamente corretas ou orientadas pela discursividade dominante, decidimos solicitar duas representações conceptuais que, segundo os professores inquiridos, melhor traduziam o entendimento que os seus pares atribuiam aos referidos conceitos. Para cada um dos conceitos foi apresentado um conjunto de expressões das quais apenas duas se encontravam formuladas de acordo com os referenciais teóricos em que se fundamentou a presente investigação. (ABELHA, 2011, p. 186-187).

\section{Currículo}

No que se refere à noção de currículo, os dois itens mais escolhidos foram: "Conjunto de aprendizagens consideradas socialmente necessárias aos alunos num dado contexto e tempo", com 68, 9\% das escolhas, e "Projeto organizador das aprendizagens socialmente necessárias em cada contexto”, com 48,1\% das escolhas. Ambas as definições mais escolhidas vão de encontro à exposição teórica deste trabalho. Relativamente à primeira expressão, Roldão (2007b, p. 16) considera que, se pretendermos enquadrar este conceito num contexto histórico-cultural, então "currículo escolar é - em qualquer circunstância o conjunto de aprendizagens que, por se considerarem socialmente necessárias num dado tempo e contexto, cabe à escola garantir e organizar".

No entanto, refere também que a verdadeira concepção de currículo se assume como um "projeto contextualizado e diferenciado, [que] garante o conjunto de aprendizagens consideradas como imprescindiveis à sobrevivência social e cultural dos alunos" (ROLDÃO, 2007b, p. 23), o que se ajustará mais à segunda expressão mais escolhida. Além disso, e ainda de acordo com esta autora, como o que se deseja muda, as necessidades sociais e econômicas 
e as ideologias educativas variam, a interação entre as diferentes forças conflui no currículo escolar, que corporiza as mutações vividas, instituindo como fundamentais determinadas aprendizagens, naquele espaço temporal e naquele contexto educativo (ROLDÃ0, 2007b).

Estas duas opções sugerem, por parte dos professores inquiridos, uma certa apropriação deste conceito.

Contudo, não podemos deixar de referir que os dois outros itens selecionados, e com um grau de concordância ainda significativo (46,2\% e 36,8\% respectivamente), encaram o currículo como "Programa da disciplina" e como "Corpo uniforme de matérias a ensinar", ambas visões bastante redutoras e fortemente rebatidas pelos diversos autores ao longo de toda esta exposição, principalmente após a Reorganização Curricular do Ensino Básico, promulgada através do Decreto-Lei n 6/2001, de 18 de janeiro.

Estes dois últimos entendimentos sobre o conceito de currículo implicam a divisão da escola em pequenos grupos, o que acarreta consequências perniciosas não só na construção de "um projeto comum e para a necessária orientação disciplinar do currículo, como também para a continuidade no acompanhamento do progresso dos alunos e para a comunicação fluente que requer a coordenação horizontal e vertical” (PÉREZ GÓMEZ, 2000).

De certo modo, e tendo em conta que, à parte a primeira seleção que teve um peso percentual claro e inconfundivel $(68,9 \%)$, todas as outras escolhas tiveram poucas variações percentuais, podemos inferir, e de acordo com Abelha (2011), que ainda há uma certa tendência de cariz tradicional, que poderá significar algum distanciamento entre a teoria e a prática.

\section{Desenvolvimento curricular}

Os dois itens mais selecionados em relação ao conceito de desenvolvimento curricular foram "Modo como em cada escola e turma se planificam, desenvolvem e avaliam as diferentes situações de ensino e aprendizagem, tendo por referência as metas e opções de gestão curriculares assumidas", com uns expressivos 83\%, e "Concretização do plano sequencial do ensino e da aprendizagem, privilegiando-se as regras de previsão, temporalidade e precisão dos resultados", com 56,6\%.

Também aqui se verifica uma apropriação dos conceitos por parte dos professores inquiridos, pois o primeiro item selecionado aproxima-se das noções veiculadas por Roldão (2007b), para quem as aprendizagens dos alunos incluem obrigatoriamente um determinado número de competências consideradas essenciais, nomeadamente no que diz respeito a muni-los de ferramentas que os preparem para o domínio da organização e da formulação do conhecimento.

Cabe à escola preparar os seus alunos para a diversidade de culturas com que hoje em dia todos nos deparamos, tornando-os competentes na articulação e uso das respectivas ferramentas (ROLDÃO, 2007a). Na mesma linha de raciocínio, para Pacheco (2001, 14-48):

[...] o termo desenvolvimento curricular é utilizado para expressar uma prática, dinâmica e complexa, processada em diversos momentos de modo a formar um conjunto estruturado com quatro componentes fundamentais: justificação teórica, elaboração/planificação, operacionalização e avaliação. 
Já no que diz respeito ao segundo item mais escolhido, ele denota "um enfoque predominante na execução, relegando os aspectos de concepção, monitorização, reflexão e reconceptualização para segundo plano”, o que corresponde a uma visão dos professores em que há "predominância da execução curricular na escola e a ausência de concepção curricular” (ROLDÃO, 2007a).

Não podemos ignorar que a terceira opção mais escolhida, e com uns consistentes $56,6 \%$, considera o conceito de desenvolvimento curricular como sendo a "Concretização do plano sequencial do ensino e da aprendizagem, privilegiando-se as regras de previsão, temporalidade e precisão dos resultados”, centrando o desenvolvimento curricular numa perspectiva por objetivos, separando a teoria e a prática, e onde o professor assume o papel de simples executor do que está previamente definido por outros. Nessa perspectiva, o professor é encarado como transmissor de conhecimentos a alunos passivos, vistos como receptáculos (ABELHA, 2011).

\section{Gestão curricular}

Quanto à gestão curricular, as duas opções mais escolhidas foram: "Decisão, a nível de Conselho de Turma e em articulação com os Departamentos Curriculares, sobre o que ensinar e porquê, como, quando, com que prioridades, com que meios, com que organização, com que resultados", com 48,1 \% das escolhas dos inquiridos, seguido de "Decisão, a nível de Departamento Curricular, sobre o que ensinar e porquê, como, quando, com que prioridades, com que meios, com que organização, com que resultados”, com 45,3\%.

Também nesta dimensão o item com maior valor percentual denota a compreensão dos desenvolvimentos dos processos de gestão curricular integradores das diferentes disciplinas. Há uma apropriação do conceito em questão, que reflete a lógica do professor não como simples executor, mas como tomador de decisões sobre o currículo, que vai de encontro aos pressupostos de Roldão (2007a), que considera que a gestão curricular implica analisar, decidir, concretizar a decisão, avaliar o desenvolvimento e os resultados, prosseguir, reorientar ou mesmo abandonar a decisão inicialmente tomada.

Por outro lado, a segunda opção entra em contradição com a primeira, pois colocar o nível de decisões no contexto de departamento "poderá condicionar o desenvolvimento dos processos de gestão curricular integradores das diferentes disciplinas” (ABELHA, 2011, p. 189). Então, para que seja possível realizar a gestão do currículo, é necessário, de acordo com Roldão (2007b, p. 34), "deslocar e diversificar os centros de decisão curricular, e por isso visibilizar níveis de gestão que até aqui tinham pouca relevância neste campo", o que "exige às escolas e aos professores, enquanto decisores do currículo, a construção de caminhos curriculares mais ricos, reflexivos, relacionais e rigorosos” (ROLDÃo, 2007b, p. 34).

A terceira definição de gestão escolar mais escolhida, "Reconstrução contextualizada do currículo proposto a nível nacional”, com 44,3\%, seria, além da que foi mais selecionada, a que mais se aproximaria dos referenciais teóricos aceites neste estudo.

No entanto, e excetuando a expressão "Processo de decisão exclusivo dos departamentos sobre a sequência dos conteúdos e sua calendarização", que somente obteve 16\% das escolhas, a expressão que aparece em quarto lugar, com 42,5\%, "Modo 
como se organizam os diferentes conteúdos disciplinares em termos da sua divisão pelo ano, para as várias turmas", aproxima-se muito do nível de valor percentual das três anteriores, o que pode sugerir alguma confusão por parte dos inquiridos; no entanto, e conforme referido inicialmente, o item com maior valor percentual das escolhas assenta sobre os pressupostos teóricos apresentados neste trabalho.

\section{Projeto}

Os dois itens mais escolhidos para conceituar projeto, e com valores bem distintos de todas as outras expressões, foram "Conjunto de atividades de ensino e aprendizagem dirigidas a finalidades determinadas, que correspondam a necessidades sentidas pelos agentes envolvidos", com 81,1\%, e "Modo de concretizar as orientações curriculares de âmbito nacional face a um contexto específico, implicando uma constante avaliação de resultados e possiveis reformulações", com 67\%. De referir que a opção "Sinônimo de programa" só obteve 2,8\% das respostas dos inquiridos.

Os resultados refletem que esse conceito tem, da maior parte dos professores inquiridos, um "entendimento teoricamente fundamentado", mas que, de acordo com Abelha (2011, p. 187-188), poderá estar relacionado com o fato de "constar, frequentemente, nos documentos oficiais e estar associado a normativos a cumprir na prática quotidiana das escolas". Além disso, podemo-nos questionar se a apropriação do conceito não será apenas nos plano discursivo, ou se realmente "reflete uma realidade, tem uma finalidade e é concebido e gerido pelos atores educativos envolvidos" (ROLDÃo, 2007b).

No entanto, de acordo com as opções com maior valor percentual, podemos inferir que estamos perante uma escola que acredita nos seus docentes, incentivando-os não só à reflexão, mas à própria ação e, dessa forma, em colaboração com todos os seus elementos, a construir o seu próprio projeto educativo em harmonia com a realidade em que se insere, e num questionamento e avaliação permanentes, com vista à construção de uma escola cada vez melhor e com um conhecimento cada vez mais aprofundado sobre educação.

\section{Trabalho colaborativo}

A “Tomada conjunta de decisões sobre aspectos inerentes à prática letiva, tais como planificações, construção de materiais didáticos, critérios de avaliação e partilha de experiências pedagógicas", com 78,3\%, e "Processo de interação em que os professores, com base numa relação de interdependência e de responsabilidade, decidem sobre as opções curriculares e práticas docentes a adotar”, com 57,5\%, foram os dois itens mais escolhidos nesta dimensão, a do trabalho colaborativo. Ambos os itens selecionados refletem uma representação conceitual concordante com a fundamentação teórica deste trabalho, pois, e de acordo com Alarcão (2003), denotam a necessidade de compreensão pelo outro, de estabelecer com os seus pares relações de interação e de intercompreensão, que passam necessariamente pela capacidade de saber ouvir, com respeito pelas diferentes opiniões, e, ainda de acordo com a mesma autora (2003), de 
deixar para trás o individualismo tão característico da classe docente, acreditando-se como parte ativa de um todo a que se pertence.

Também de acordo com Costa Lobo (2011), e baseando-se em estudos realizados por Kagan (1985) e Slavin (1987), os sujeitos trabalham melhor em conjunto se houver uma interdependência positiva, fazendo com que todos procurem as soluções necessárias para um determinado trabalho a realizar, tentando resolver conjuntamente as tarefas que lhes são propostas.

Os itens com maior valor percentual levam-nos a deduzir que, de uma maneira geral, neste agrupamento, os professores envolvidos partilham objetivos, atitudes e ideias; com um bom ambiente de trabalho, não só no que diz respeito aos relacionamentos interpares, mas também à planificação curricular, pois partilham diferentes opiniões e experiências. Tais itens denotam ainda uma interdependência entre os docentes, pois, ao trabalharem em projetos comuns, os professores partilham preocupações que, em conjunto, procuram ultrapassar, levando-os a partilhar aprendizagens, o que, por sua vez, melhora as práticas pedagógicas. Assim, todo esse processo permite um maior desenvolvimento profissional, que por sua vez se reflete no trabalho docente, conduzindo a melhorias em todo o processo educativo escolar.

De referir que só 2,8\% dos respondentes considerou que o trabalho colaborativo era uma "Perda de tempo porque cada professor é que conhece os seus alunos", e só 17\% considerou o item "Planificação de aulas e atividades em conjunto, de modo a garantir materiais comuns e sequências paralelas", o que reflete as percepções dos professores deste agrupamento relativamente à importância do trabalho conjunto.

Um pouco preocupante, no nosso ponto de vista, é o fato de 42,5\% (terceira opção mais escolhida) ter considerado o item "Trabalho de concepção e planificação de atividades curriculares, entre professores que lecionam a mesma disciplina e ano letivo", o que é uma visão bastante simplista do conceito de trabalho colaborativo, rebatida pela conceptualização teórica deste trabalho, e considerada como um constrangimento às práticas colaborativas, muitas vezes unicamente associadas à "planificação e preparação de atividades de natureza 'extracurricular" (FULLAN; HARGREAVES, 2001) e à "partilha e construção conjunta de materiais pedagógicos” (MCLAUGHLIN; TALBERT, 2001, grifos dos autores), que, quando se realizam, estão normalmente limitadas a professores que lecionam a mesma área disciplinar ou o mesmo ano de escolaridade.

Este tipo de pensamento vai de encontro àquilo que diversos autores intitulam como balcanização e que se destina fundamentalmente a promover a planificação conjunta e a partilha interpares.

0 trabalho balcanizado é realizado em pequeno grupo, o que, de acordo com Hargreaves (1998), impede os professores de ver a escola como um todo e, segundo González González (2006), conduz a subculturas que se refletem em modos de pensar e fazer que podem não ter a ver com a cultura geral da escola e que, assim sendo, se traduzem em consequências negativas no que diz respeito ao desenvolvimento profissional dos professores, acabando por se refletir igualmente de forma negativa nas aprendizagens dos alunos. 


\section{- Escala de satisfação com as dinâmicas de trabalho docente}

\section{Direção}

A direção apresenta uma moda de 3 (numa escala de 1 a 4), que corresponde ao concordo nos itens "Gere eficazmente os recursos humanos, os espaços e os equipamentos" e "Integra diferentes contributos/opiniões na tomada de decisão". Todos os outros itens dessa dimensão apresentam uma moda de 4, que corresponde ao "concordo plenamente", ou seja, no que se refere a: "Apoia o desenvolvimento profissional do pessoal docente", "Distribui o serviço aos docentes, depositando expectativas elevadas nos mesmos", "Atende os diferentes elementos da comunidade educativa, ouvindo-os, com vista à resolução dos seus problemas", "Estimula o desenvolvimento profissional dos docentes" e "Elabora, em conjunto com a comunidade educativa, o projeto educativo para o agrupamento", com médias que variam entre 3,3 e 3,7.

Pelas respostas obtidas, podemos verificar que o nível de satisfação do corpo docente deste agrupamento com a direção é bastante elevado.

Então, e reforçando a ideia de que nesta dimensão os professores não se referem unicamente à pessoa do diretor, mas a toda a equipe diretiva, podemos inferir que, neste agrupamento, e uma vez que o professor não pode agir isoladamente na sua escola, se criaram "condições de reflexividade individuais e coletivas, sendo ela própria reflexiva" (ALARCÃo, 2003, s/p), através de uma liderança que se considera eficaz e que transmite aos seu professores energia, entusiasmo e valorização.

Ao longo de toda a exposição teórica, pudemos constatar que a liderança de uma escola pode ou não contribuir para uma cultura colaborativa; logo, salientamos a sua enorme importância para a cultura instituída num determinado estabelecimento de ensino.

\section{Subdepartamento e coordenação de ano}

À exceção dos itens “Define estratégias comuns para apoio a alunos com dificuldades de aprendizagem”, "Define estratégias tendentes ao envolvimento dos encarregados de educação no acompanhamento dos seus educandos" e "Analisa e apresenta propostas de formação dos professores", que apresentaram a moda de 3 "concordo", todos os outros apresentaram a moda 4 "concordo plenamente", sendo eles: "Promove a articulação curricular", "Articula as atividades das áreas disciplinares", "Analisa e reflete sobre práticas educativas", "Analisa os resultados de avaliação dos alunos", "Dá conhecimento de informações emanadas do Conselho Pedagógico", "Elabora as planificações das unidades letivas", "Seleciona/elabora os materiais pedagógicos", "Discute as estratégias de diferenciação pedagógica", "Elabora testes ou outros instrumentos de avaliação", "Define critérios de avaliação", "Procura soluções para minimizar problemas de insucesso escolar", "Avalia a eficácia das estratégias de ensino utilizadas", "Elabora planos de ação" e "Avalia a eficácia das medidas de apoio implementadas". Esta dimensão apresentou médias entre 3,1 e 3,8.

A partir da análise desses dados, podemos concluir que existe uma cultura colaborativa, de forma continuada e concertada (ARAÚJO, 2012); no entanto, aqui, nesta 
dimensão, ela está assente ao nível do ensino da mesma área disciplinar (subdepartamento), ou do mesmo ano de escolaridade (coordenação de ano), mas que não pode ser colocada em causa, pois são formas de trabalho deste agrupamento, que partem do particular para o geral, o que iremos verificar na dimensão seguinte.

\section{Conselhos de turma e unidades educativas}

Para a dimensão Conselhos de turma e unidades educativas, obtivemos moda de 4 em praticamente todos os itens, excetuando: "Discute as linhas orientadoras da ação do Agrupamento", "Define estratégias tendentes ao envolvimento dos Encarregados de Educação no acompanhamento dos seus educandos” (também com moda 3 na dimensão anterior, denotando que grande parte dos respondentes considera que é um trabalho ainda em evolução, com necessidade de melhoria) e "Avalia a eficácia das estratégias de ensino" (que obteve a moda 4 na dimensão anterior, significando que, de acordo com a percepção dos professores inquiridos, não é tão trabalhado nesta dimensão). Com moda de 4 aparecem-nos os seguintes itens: "Discute as linhas orientadoras da ação da escola/ unidade educativa”, "Analisa e reflete sobre as práticas educativas”, "Analisa os resultados de avaliação dos alunos", "Dá conhecimento de informações emanadas do Conselho Pedagógico", "Elabora, analisa o cumprimento/implementação e reformula o projeto próprio de turma/unidade educativa", "Faz o planejamento de atividades interdisciplinares", "Procura soluções para minimizar problemas de insucesso escolar", "Organiza atividades de enriquecimento curricular, "Elabora planos de apoio", "Define estratégias comuns para apoio a alunos com dificuldades de aprendizagem", "Avalia a eficácia das medidas de apoio implementadas", "Analisa problemas pessoais dos alunos", "Analisa participações de ocorrência apresentadas por alunos", "Analisa participações de ocorrências apresentadas por Encarregados de Educação", "Analisa problemas disciplinares da turma" e "Define critérios de atuação para a turma". Nesta dimensão, a média é de 3,3 a 3,7, o que evidencia um elevado grau de satisfação do corpo docente no que diz respeito a essa dimensão.

Também nesta dimensão deduzimos a implementação de uma cultura colaborativa, que apela à responsabilidade e reflexão partilhadas, desenvolvendo qualidades tanto individuais como profıssionais que irão contribuir para a melhoria de todo o processo de ensino e aprendizagem.

Assim, este agrupamento encara os seus professores como agentes ativos, responsáveis e autônomos, levando-os a refletir com os pares para, em conjunto, melhorarem as suas práticas, não só no que diz respeito à docência, mas também ao que podem fazer para minorar e ultrapassar os problemas da escola.

Em suma, podemos considerar que estamos perante uma escola reflexiva e dinâmica, que se preocupa em superar os constrangimentos através da procura constante de estratégias adequadas, conducentes a uma melhor prática pedagógica, que assenta na formação, na investigação e na socialização.

Também nesta dimensão (que abrange igualmente a anterior), vamos nos remeter ao Relatório de avaliação externa, que referencia: 
[...] [o] trabalho colaborativo, ao nível de departamento curricular, dos professores do mesmo grupo de recrutamento/ano de escolaridade, das equipas pedagógicas, de reuniões de estabelecimento é evidenciado na elaboração das planificações e materiais pedagógicos, na reflexão sobre práticas pedagógicas e resultados alcançados, na partilha de experiências, mas também na preparação de diversas atividades educativas comuns e na implementação das mesmas, com reflexos na melhoria do ambiente escolar e da progressiva da qualidade do serviço educativo prestado. (AGRUPAMENTO..., 2013d, 2013, p. 5).

\section{Cultura do agrupamento}

Mais uma vez, com moda majoritariamente 4 temos os itens: "As normas e o regulamento da escola são aplicados", "Os alunos são encorajados a trabalhar com empenho", "Os alunos são reconhecidos quando desenvolvem bom trabalho", "Os alunos são informados, em tempo oportuno, dos assuntos relevantes da política educativa", "Os professores são reconhecidos quando desenvolvem bom trabalho", "Os professores são motivados para participar em atividades de desenvolvimentos/ projetos", "Os professores são informados, em tempo oportuno, dos assuntos relevantes de política educativa”, "Os não docentes são reconhecidos quando desenvolvem bom trabalho", "Os pais são motivados para participar nas atividades do Agrupamento", "A comunidade escolar é motivada para participar nas atividades do Agrupamento" e "0 Agrupamento é um lugar disciplinado e seguro". Com moda 3, temos os seguintes itens: "As expectativas acerca dos alunos são elevadas", "A comunidade escolar envolve-se na tomada de decisões" e "Os espaços das escolas encontram-se limpos e arranjados". As médias situam-se entre 3,2 e 3,7. Perante esses resultados, deduzimos que há um elevado nível de concordância com a cultura vigente neste agrupamento. A maioria dos professores sente satisfação em trabalhar neste estabelecimento e reconhece nele várias qualidades.

Estamos perante um agrupamento motivador ao diálogo e à partilha e, seguindo a linha de raciocínio de Brzezinsk (2001), é uma escola com uma cultura interna própria, autônoma, participativa e democrática, que constrói o conhecimento de forma coletiva. Então, e segundo Hargreaves (1998), possibilita ainda um aperfeiçoamento profissional contínuo de todos os intervenientes.

Remetemo-nos, novamente, para o Relatório de avaliação externa, que refere que está

[...] instituída uma cultura de rigor e exigência, evidenciada na uniformização de documentos e procedimentos, no estabelecimento de metas progressivamente mais ambiciosas por ano letivo e na reflexão sobre metodologias e práticas que visam a melhoria dos resultados e encontrar soluções adequadas para os eventuais desvios. Os alunos são estimulados a desenvolver todas as suas capacidades, através do reforço positivo, da adequação dos apoios e do reconhecimento do mérito académico. Releva-se, ainda, o empenho do Agrupamento na transposição e adequação das melhores práticas de escolas de referência para a sua realidade interna, numa atitude positiva de melhoria permanente (AGRUPAMENTO..., 2013e, p. 5). 


\section{Aspectos positivos do agrupamento}

Na dimensão Aspectos positivos do agrupamento, a moda foi maioritariamente 3: "Motivação dos docentes", "Interação do Agrupamento com a comunidade", "Bom estado ou adequação das instalações", "Recursos materiais suficientes", "Apoio dos órgãos de gestão" e "Ofertas de formação suficientes". Os itens "Cooperação entre os docentes" e a "Liderança dos órgãos de direção da escola" obtiveram moda 4, o que denota um elevado grau de satisfação do corpo docente relativamente a esses dois aspectos. A média entre 3,0 e 4,0 revela um nível elevado de concordância quanto a uma visão positiva por parte dos respondentes face ao agrupamento onde estão inseridos e que se coaduna perfeitamente com o resultado das dimensões anteriormente referidas.

\section{Problemas do agrupamento}

Esta dimensão apresentou médias entre 1,77 e 2,26, que, juntamente com a moda 1 em todos os itens - "Desmotivação dos docentes", "Falta de colaboração entre os docentes", "Falta de interação do Agrupamento com a comunidade", "Falta de liderança dos órgãos de direção da escola" e "Apoio insuficiente dos órgãos de gestão" -, vão de encontro às conclusões anteriormente referidas, pois demonstram que não há grande desagrado por parte dos respondentes relativamente a aspectos eventualmente menos positivos, o que significa que os professores inquiridos não percebem grandes problemas no agrupamento onde trabalham. Mediante os resultados apresentados, inferimos que a grande maioria dos inquiridos discorda da existência dos problemas apresentados no questionário, ou que, pelo menos, não lhes atribuem grande importância.

\section{Médias de todas as dimensões apresentadas na escala de satisfação com as dinâmicas de trabalho docente}

Relativamente à direção, e relembrando que se refere a toda uma equipe, a média é de $86,5 \%$, o que denota um elevado grau de satisfação do pessoal docente deste agrupamento quanto a esse órgão de liderança.

No que diz respeito ao subdepartamento e coordenação de ano, e também aos conselhos de turma e unidades educativas, com 87,2\% e 86\% respectivamente, são também indicadores de que os docentes consideram que, nesses órgãos, realiza-se um trabalho numa base igualitária, com verdadeira ajuda mútua, em que os intervenientes participam em conjunto de forma a atingirem os objetivos estabelecidos (BOAVIDA; PONTE, 2002), o que contribui para a melhoria da própria escola e dos resultados dos alunos.

A cultura do agrupamento aparece com um grau de satisfação de 85,7\%, o que indica um bom clima escolar, com uma cultura de agrupamento que reúne bastante consenso por parte dos professores. Oitenta e um, vírgula três por cento consideram que o Agrupamento tem bastantes aspectos positivos, e 47,7\% percebem problemas no nele. 


\section{Síntese das ideias obtidas após a discussão dos resultados}

Resumindo as ideias obtidas após a discussão dos resultados, podemos inferir que a noção que os professores do agrupamento em estudo têm sobre os conceitos apresentados no inquérito - currículo, desenvolvimento curricular, gestão curricular, projeto e trabalho colaborativo - se aproxima, em grande parte dos casos, do enquadramento teórico apresentado neste trabalho e, logo, das várias definições dos diferentes autores estudados. Os participantes desta investigação revelam fazer atualização da literatura de especialidade neste domínio; fato que, contudo, não remete necessariamente para a apropriação das leituras e para a sua aplicação e operacionalização ao quotidiano da prática docente.

De acordo com Ferreira (2003, p. 1022), os professores, à semelhança do que, em parte, também acontece neste agrupamento, identificam-se, de uma maneira geral, "com os seus pares do mesmo nível de ensino e ainda de forma mais restrita dentro do seu grupo disciplinar”, o que Hargreaves (1998) designa por identificação pessoal e que se justifica pelo fato de os professores fazerem a sua socialização em torno de uma determinada área do saber, o que fragiliza o estabelecimento de relações com outros grupos de professores.

Relativamente aos aspectos positivos do agrupamento, a grande maioria dos professores inquiridos apresenta uma visão agradável, não dando grande relevância aos aspectos negativos.

Assim, e no que diz respeito ao clima escolar, podemos afirmar que é percebido de forma positiva pela maioria dos inquiridos. No entanto, a noção de clima escolar pode variar, não existindo uma definição única, pois resulta principalmente de fatores de natureza imaterial, como as atitudes, os valores e os preconceitos de professores e alunos, o tipo de gestão etc. e não tanto de aspectos físicos, sendo normalmente usada como referência à natureza do ambiente percebido numa escola (COHEN et al., 2009).

Nas dinâmicas de trabalho docente, este grupo de respondentes demonstra um grande sentimento de pertença relativamente ao Agrupamento onde a investigação foi realizada, identificando-se com a equipe de liderança.

De referir, no entanto, que neste agrupamento se vem trabalhando, ao longo dos anos, no sentido de construir um projeto comum, envolvendo todos os professores, o que requer comunicação e socialização entre os diversos intervenientes.

Nesse sentido, Hargreaves (1998) enumera as vantagens do trabalho colaborativo, nomeadamente no que diz respeito ao apoio moral, que ajuda a ultrapassar fracassos, à eficiência acrescida, pois o trabalho em conjunto evita redundâncias, à eficácia melhorada devido à partilha de ideias, experiências e responsabilidades, à sobrecarga de trabalho reduzida, com a partilha de tarefas e de responsabilidades, à certeza situada, pois, ao trabalharem coletivamente, reduzem os sentimentos de insegurança, à capacidade de reflexão acrescida, que promove o diálogo e a reflexão sobre as práticas curriculares, às oportunidades de aprendizagem porque, entre todos, produzem conhecimento, e ao aperfeiçoamento contínuo, em que a mudança passa a ser encarada como uma forma de ultrapassar problemas diagnosticados, num processo contínuo de aperfeiçoamento. 


\section{Considerações finais}

Tendo sido a nossa investigação baseada unicamente no inquérito por questionário, com recurso a questões fechadas, receamos que tenha havido um certo condicionamento de caráter politicamente correto de muitas das respostas dos inquiridos, o que teria reduzido a obtenção de informação mais relevante (ABELHA, 2011, p. 395). Além disso, também de acordo com Abelha (2011, p. 396), “a administração não presencial do questionário não assegura a sinceridade dos inquiridos na resposta, a correta interpretação das questões nem o seu preenchimento individual". Queremos, no entanto, acreditar que a grande maioria dos inquiridos respondeu a este questionário com sinceridade e de forma consciente.

De qualquer forma, todas as ilações retiradas aquando da discussão dos resultados estão em consonância com o Relatório de avaliação externa de 2013.

Não podemos, apesar de tudo, deixar de referir que grande parte do trabalho colaborativo neste agrupamento é regulado pela equipe diretiva, através da organização das diversas reuniões, o que, no entanto, não impede um verdadeiro empenho da parte de todos no sentido de tentar ultrapassar os obstáculos que lhes vão sendo colocados. Essas reuniões estão para além do simples dar-se bem com os pares ou a simples partilha de material didático. Acreditamos que, apesar de impostas, todos os docentes assumem os pontos da agenda de trabalho dessas reuniões com responsabilidade e reflexão, com vista a um "aperfeiçoamento coletivo e uma disponibilidade e postura crítica quanto ao trabalho realizado" (LITTLE, 1990, p. 512).

Uma vez que fazemos parte do agrupamento em estudo, sabemos que, muitas vezes, ao sentirem a necessidade da partilha conjunta para ultrapassar determinados obstáculos, normalmente entre os diferentes ciclos e para articularem conhecimentos, são os próprios professores que, de forma autônoma e responsável, decidem realizar um trabalho colaborativo, através da negociação entre pares, e assente numa visão integradora do projeto educativo. Podemos então dizer que se promove uma maior interatividade entre os colegas dos diferentes estabelecimentos de ensino pertencentes a este agrupamento, com vista a uma aprendizagem coletiva que vai "para além da mera aceitação das diretrizes curriculares definidas externamente, ou da simples definição dos objetivos curriculares gerais a atingir" (LIMA, 2002, p. 12).

Contudo, há ainda uma grande carga burocrática ritualizada, com excesso de papéis a serem preenchidos e que nem sempre são bem aceitos pelos professores, que os encaram como uma sobrecarga de trabalho.

Não assumimos este estudo como um fim em si mesmo, mas encarando a colaboração como o tipo de trabalho entre professores mais adequado às dinâmicas docentes, capaz de ajudar as escolas de hoje a enfrentar os desafios que lhes são colocados.

Em suma, este agrupamento, pelas análises possíveis através das respostas ao questionário fornecido, pode ser considerado um exemplo de boas práticas colaborativas, possuidor de uma gestão eficaz e uma liderança que apoia, incentiva e motiva os seus docentes. Pode, então, ser considerado um caso de sucesso e servir de referência a outros estabelecimentos de ensino, TEIP ou não. 
Esta investigação deixa em aberto potenciais cenários futuros de investigação e intervenção no domínio da escola reflexiva, privilegiando as culturas escolares de referência.

\section{Conclusão}

A missão da escola atual é antecipar o futuro, preparando os alunos para trabalhos que ainda não existem, através da criação de ideias e de soluções para problemas que ainda não foram identificados, com tecnologias ainda não totalmente desenvolvidas. Com base numa escola historicamente desigual, estas autoras questionam-se acerca da possibilidade de uma escola capaz de enfrentar o desafio de desenvolver competências cada vez mais complexas, não apenas para alunos de elite, mas para todos os alunos que a integram.

Deste modo, para que a escola possa ultrapassar as desigualdades entre os alunos e conseguir o desenvolvimento de todos os seus estudantes, Darling-Hammond (2010) apresenta cinco elementos-chave: estabelecer objetivos de aprendizagem significativos, baseados em conteúdos e competências essenciais para o século XXI; garantir a oportunidade de ensino, com aprendizagens de qualidade, através da responsabilização no uso de recursos e compromisso com os resultados; oferecer igualdade de condições e, logo, de oportunidades, através de recursos igualitários e adequados; estabelecer padrões profissionais elevados, apoiando os docentes no seu desenvolvimento e aperfeiçoamento; e criar um currículo assente no conteúdo crítico e no desenvolvimento de habilidades, através da organização das escolas focadas nas aprendizagens, tanto de alunos como de professores.

Podemos então dizer que os TEIP foram criados nessa linha de pensamento, pois têm como objetivo primordial impulsionar, de acordo com o Despacho 147-B-ME/96, "o desenvolvimento e a formação de todos os cidadãos em condições de igualdade de oportunidades e no respeito pela diferença e autonomia de cada um" (FERREIRA; TEIXEIRA, 2010, p. 377) e constituem "a principal modalidade de intervenção atual do Estado Português no combate ao insucesso, abandono e absentismo escolares e que tem tido um desenvolvimento muito significativo nos últimos anos, abrangendo cerca de 10\% de agrupamentos escolares" (DIAS et al., 2011, p. 38).

Com este trabalho, pretendemos transmitir a noção de que a necessária mudança do cenário educativo atual, desenvolvendo a igualdade de oportunidades para todos, só é possivel através do trabalho colaborativo entre professores, pois esse é o tipo de trabalho que propicia o desenvolvimento profissional docente, que se irá refletir na qualidade do ensino e, logo, nas aprendizagens dos alunos.

Assim, nas escolas onde o trabalho docente colaborativo predomina, no que diz respeito à tomada conjunta de decisões para a concretização de um determinado projeto, o trabalho docente cooperativo permite o desenvolvimento das práticas do ensino (DAY, 2001) e potencia o desenvolvimento de um trabalho intenso e de responsabilidade coletiva, com a partilha e a discussão das incertezas e dos insucessos (ABELHA; MARTINS; COSTA, 2008).

Então, atualmente, há um enfoque na implementação das melhorias do desempenho de toda a comunidade educativa, que passa não só pelas práticas docentes, como também pelas próprias organizações escolares. Todos os aperfeiçoamentos previstos pressupõem 
a necessidade de alteração de uma cultura individualista, para a adoção não apenas de culturas colaborativas assentes na reflexão comum sobre opiniões e apropriações de conceitos, mas também de um trabalho de equipe capaz de criar projetos curriculares integradores e, principalmente, inclusivos de todos os alunos. Nesse sentido, reiteramos que é imprescindível que a gestão curricular, adaptável às diferentes realidades, permita que o aluno, ao invés de se limitar a estar, por obrigação, integrado na escola, esteja verdadeiramente incluído na mesma.

Também para Santiago (2000, p. 38), o “que mais interessa para a aprendizagem organizacional são, na realidade, os processos coletivos que sustentaram a sua construção e/ou seleção conjunta dos indicadores e instrumentos e a procura de soluções para os problemas detectados com a avaliação”.

Essa reorganização implica a adequação do currículo nacional à(s) realidade(s) de cada escola, valorizando a diversidade de metodologias e de estratégias a aplicar em todo o processo de ensino-aprendizagem. Dessa forma, o poder de decisão deixa de vir unicamente de cima, passando também a escola a deter um papel preponderante em todo esse processo, o que, de igual forma, implica uma maior responsabilização da mesma e envolve os professores em várias decisões, nomeadamente quanto à construção e gestão curricular, exequível somente através do trabalho colaborativo.

Assim, e tomando como exemplo a presente investigação, podemos afirmar que se podem ultrapassar os inúmeros obstáculos colocados hoje aos estabelecimentos de ensino, instituindo uma mudança de paradigma tanto metodológico como pedagógico. Só com o envolvimento de todos os atores educativos, numa perspectiva colaborativa, com verdadeiros momentos de reflexão acerca de interesses comuns, espírito de entreajuda e partilha de experiências, e através do diálogo, do confronto de ideias e do respeito pelo outro, é possível o desenvolvimento intelectual com vista a um melhor desempenho profissional e até pessoal e, logo, com significativas melhorias das apropriações realizadas pelos alunos.

Uma vez que, e de acordo com os diversos autores estudados, a docência portuguesa continua a seguir um cariz tradicional, com forte incidência num trabalho individualista, como futuras sugestões de trabalho, consideramos que seria importante estender este tipo de estudo de caso, centrado no mesmo objeto, a outros contextos escolares, de maneira a contribuir para um melhor conhecimento do tema em estudo e a tentar perceber se há realmente uma nova tendência, com maior espírito de colaboração.

\section{Referências}

ABELHA, Marta Cristina Lopes. Trabalho colaborativo docente na gestão do currículo do ensino básico: do discurso às práticas. 2011. Tese (Doutoramento em Didática) - Universidade de Aveiro, Aveiro, 2011.

ABELHA, Marta Cristina Lopes; MARTINS, Idalina, COSTA, Nilza. Colaboração docente na área das ciências físicas e naturais: uma aula em regime de co-docência sobre chuvas ácidas. Ciência em Tela, Aveiros, v. 1, n. 2, p. 1-10, 2008. 
ABELHA, Marta Cristina Lopes; MACHADO, Eusébio André; COSTA-LOBO, Cristina. Colaboração docente em contexto educativo angolano: potencialidades e constrangimentos. In: ENCONTRO LUSO-BRASILEIRO SOBRE 0 TRABALHO DOCENTE E FORMAÇÃO, 2., 2014, Porto. Atas do...: Trabalho docente e formação: políticas, práticas e investigação: pontes para a mudança. Porto: CIIE, 2014. p. 5368-5380. ISBN: 978989-8471-13-0.

AGRUPAMENTO DE ESCOLAS D PEDRO I. Projeto educativo. Vila Nova de Gaia: [s. n.], 2013a. Disponível em: <http://www.dpedro.net/images/2013_2014/documentos/Projeto_Educativo_2013-14.pdf>. Acesso em: 2015.

AGRUPAMENTO DE ESCOLAS D PEDRO I. Projeto educativo. Vila Nova de Gaia: [s. n.], 2013b. Disponível em: <http://www.dpedro.net/images/2013_2014/documentos/Projeto_Educativo_2013-14.pdf>. Acesso em: 2015.

AGRUPAMENTO DE ESCOLAS D PEDRO I. Projeto curricular. Vila Nova de Gaia: [s. n.], 2013c. Disponível em: <http://www.dpedro.net/images/2014_2015/Documentos/PAA\%2014-15.pdf>. Acesso em: 2015.

AGRUPAMENTO DE ESCOLAS D PEDRO I. Relatório de avaliação externa. Vila Nova de Gaia: [s. n.], 2013d. Disponível em: <http://www.dpedro.net/images/estrutura_site/documentos_fundamentais/rel_ ae_\%20agrup.pdf>. Acesso em: 2015.

AGRUPAMENTO DE ESCOLAS D PEDRO I. Relatório de avaliação externa. Vila Nova de Gaia: [s. n.], 2013e. Disponível em: <http://www.dpedro.net/images/estrutura_site/documentos_fundamentais/rel_ ae_\%20agrup.pdf>. Acesso em: 2015.

ALARCÃO, Isabel Tavares. Professores reflexivos em uma escola reflexiva. São Paulo: Cortez, 2003.

ARAÚJO, Helena Cristina dos Santos. Projetos de leitura e trabalho colaborativo: conceções e práticas de professores e professores bibliotecários. 2012. Dissertação (Mestrado em Gestão da Informação e Bibliotecas Escolares) - Universidade Aberta, Lisboa, 2012.

AZEVED0, Rui (Coord.) Projetos educativos: elaboração, monitorização e avaliação - guião de apoio. Lisboa: Agência Nacional para a Qualificação, 2011. (Recursos e dinâmicas; 6). ISBN 978-972-8743-72-7.

BOAVIDA, Ana Maria; PONTE, João Pedro da. Investigação colaborativa: potencialidades e problemas. In: GTI - Grupo de Trabalho sobre Investigação. Reflectir e investigar sobre a prática profissional. Lisboa: APM, 2002. p. 43-55.

BRZEZINSK, Iria. Fundamentos sociológicos, funções sociais e políticas da escola reflexiva e emancipadora: algumas aproximações. In: ALARCÃO, Isabel Tavares (Org.). Escola reflexiva e nova racionalidade. Porto Alegre: Artmed, 2001. p. 12-41.

COHEN, Jonathan et al. School climate: research, policy, practice, and teacher education. Teachers College Record, Columbia, v. 111, n. 1, p. 180-213, 2009. 
COSTA-LOBO, Cristina. Abordagem sociocognitiva do ajustamento à carreira no ensino superior: 0 papel das atividades em grupo, da autoeficácia e dos interesses. 2011. Tese (Doutoramento em Psicologia - Psicologia Vocacional) - Escola de Psicologia da Universidade do Minho, Braga, 2011.

DIAS, Mariana et al. Políticas de intervenção prioritária em Portugal: novas políticas, novas práticas? In: ENCONTRO DO CIED, 5., 2011, Lisboa. Atas do...: escola e comunidade. Lisboa: Escola Superior de Educação de Lisboa, 2011. p. 87-96. ISBN: 978-989-95733-3-8.

FERREIRA, Isabel Ferreira; TEIXEIRA, Ana Rita. Territórios educativos de intervenção prioritária. Sociologia, Porto, v. 20, p. 331-350, 2010.

FULLAN, Michel; HARGREAVES, Andy. Por que é que vale a pena lutar? 0 trabalho de equipa na escola. Porto: Porto Editora, 2001.

GONZÁLEZ GONZÁLEZ, Ma. Teresa. Absentismo y abandono escolar: una situación singular de exclusión educativa. REICE: Revista Iberoamericana sobre Calidad, Eficacia y Cambio en Educación, Madrid, v. 4, n. 1, p. 5-27, 2006.

HARGREAVES, Andy. Os professores em tempos de mudança. Lisboa: McGraw-Hill, 1998.

HUBERMAN, Michael. 0 ciclo de vida profissional dos professores. In: NÓVOA, António (Org.). Vidas de professores. Porto: Porto Editora, 2007. p. 31-61.

KAGAN, Spencer. Cooperative learning: resources for teachers. Riverside: University of California, 1985.

LIMA, Jorge Ávila de. As culturas colaborativas nas escolas. Porto: Porto Editora: 2002.

LITTLE, Judith Warren. The persistence of privacy: autonomy and initiative in teachers' professional relations. Teachers College Record, v. 91, n. 4, p. 509-536, 1990.

MCLAUGHLIN, Milbrey W.; TALBERT, Joan E. Professional communities and the work of high school teaching. Chicago: University of Chicago Press, 2001.

PACHECO, José Augusto. Currículo: teoria e praxis. Porto; Porto Editora, 2001.

PÉREZ GÓMEZ, Anagel I. A aprendizagem escolar: da didática operatória à reconstrução da cultura na sala de aula. In: SACRISTÁN, José Gimeno; PÉREZ GÓMEZ, Anagel I. Compreender e transformar o ensino. 4.ed. Porto Alegre: Artmed, 2000. p. 3-17.

ROLDÃO, Maria do Céu. Gestão curricular: fundamentos e práticas. Lisboa: Ministério da Educação, 1999b.

ROLDÃO, Maria do Céu. Os professores e a gestão do currículo: perspetivas e práticas em análise. Porto: Porto Editora, 1999a.

ROLDÃo, Maria do Céu. Função docente: natureza e construção do conhecimento profissional. Revista Brasileira de Educação, Rio de Janeiro, v. 12, n. 34, 94-103, 2007a. 
ROLDÃO, Maria do Céu. Colaborar é preciso - questões de qualidade e eficácia no trabalho dos professores. Noesis, Lisboa, n. 71, p. 24-29, 2007b.

SANTIAGO, Rui A. A Escola também é um sistema de aprendizagem organizacional. In: ALARCÃO, Isabel Tavares (Org.). Escola reflexiva e supervisão: uma escola em desenvolvimento e aprendizagem. Porto: Porto Editora, 2000. p. 25- 41.

SLAVIN, Robert E. Development and motivational perspectives on cooperative learning: a reconciliation. Child Development, v. 58, n. 5, p. 1161-1167, 1987.

Recebido em: 14.01.2016

Aprovado em: 17.05.2016

Fernanda Bastos é doutora em educação pela Universidade Portucalense Infante D. Henrique, no Porto, em Portugal. Professora do primeiro ciclo do ensino básico, com formação em português e inglês de primeiro e segundo ciclos. Participou na elaboração da gestão flexível do currículo no Agrupamento Horizontal do Cerco do Porto.

Cristina Costa-Lobo é licenciada, mestre e doutora em psicologia, professora nos domínios da educação e da psicologia, na Universidade Portucalense Infante D. Henrique, no Porto, em Portugal, diretora do Departamento de Psicologia e Educação na mesma universidade.

Carla Santos Pereira é professora na Universidade Portucalense Infante D. Henrique, no Porto, em Portugal, doutora em matemática, mestre em probabilidades e estatística e licenciada em estatística. Tem vários anos de experiência no ensino de diversas disciplinas nas áreas da matemática e da estatística em diversas licenciaturas, mestrados e doutoramentos. 